\title{
Characteristics and Direction of Mechanical Design and Manufacturing Automation Development
}

(Chengxian College, Southeast University, Nanjing City 210088, Jiangsu, China)

\section{Introduction}

Under the context of China's technological development and gradual popularization of automation technology, mechanical design and manufacturing industry demonstrates trend of integration with automation technology and its characteristics, becoming an emerging subject and gaining great attention of industry. To further develop potential of mechanical design and manufacturing automation development, deep research and discussion about mechanical design and manufacturing automation technology should be realized, roundly improving China's mechanical design and manufacturing automation standard.

2Analysis on Contents and Characteristics of Mechanical Design and Manufacturing Automation

Mechanical design and manufacturing automation takes various industrial mechanical equipments, and design, manufacturing, operational control of mechanical and electrical products as objects, mechanical design and manufacturing as basis, integrates with computer science, automatic control technology and information technology, finds and solves all kinds of complex technical problems in mechanical design and manufacturing, better boosting mechanical design and
Published online: 30 ${ }^{\text {th }}$ Nov., 2017

Corresponding author: Yi Qian, Email:215081939@qq.com

manufacturing automation development, enhancing intelligent an automation standard of mechanical design and manufacturing products[1].

Compared to traditional simple mechanical design and manufacturing, mechanical design and manufacturing automation has intelligent and automation natures, instead of simple superposition of multiple techniques, it is unification of each technique, meets inner functional requirements of machine, conforms with inner performance criteria of products, and has scientific, intelligent and cutting-edge features.

The advantages of mechanical design and manufacturing automation, present in the following aspects: (1). Reducing probability of errors. Because mechanical design and manufacturing brings in advanced automation information technology and computer control Technology, automation collection, operation, analysis and process of mechanical design and manufacturing can be achieved by means of fast and convenient networks, so can automatic input and output of mechanical design and manufacturing information data,

\begin{abstract}
Under the background of society stepping into information age, machinery equipment manufacturing industry has undergone a dramatic change, traditional simple development model of mechanical structure has failed to adapted to the demands in the new age, old organism of organization and workflow has been short of market competitiveness, under the development with new technology and automation technology as represented, automation information technology comes to be popular in the mechanical design and manufacturing industry, meeting personalized, realtime, automatic and diverse market demands of mechanical design and manufacturing, thus better improving production efficiency of mechanical design and manufacturing, cutting mechanical design and manufacturing costs, comprehensively strengthening core competence of mechanical design and manufacturing products.
\end{abstract}

Key words: Mechanical design; Manufacturing automation; Mechanical structure 
Facturing

thus realizing rapid data processing. Compared with manual handling, it is more efficient, considerably reducing probability of errors. (2) Products with further precision. In combination of mechanical design and manufacturing and automation technology, it can be added with advanced information technology from all directions, ensuring smoothness in the course of mechanical design and manufacturing, improving integrity and high efficiency of mechanical design and manufacturing, and greatly increasing accuracy of mechanical design and manufacturing products. (3) Simplifying procedure, lowering difficulty. In combination of mechanical design and manufacturing and automation technology, it can clearly simplify operation procedure and operation mode of mechanical design and manufacturing, make complex mechanical design and manufacturing process more simplified, dramatically lowering risks and difficulties in mechanical design and manufacturing, and offering great convenience to operation staff. (4) Ensuring fair operation condition of product manufacturing. With the combination of mechanical design and manufacturing and automation technology, computer system can input relevant operational tasks and instructions in advance, realize manufacturing and processing of mechanical design and manufacturing products, make process more safe, ensure the whole process is under control, and improve the quality of mechanical design and manufacturing products. (5) Extending working life of equipment. Because of the combination of mechanical design and manufacturing and automation technology, places and causes of equipment fault can be found and analyzed by using automation technology, making sure equipment faults can be settled within least time, thus avoiding escalation of inner fault of equiment, reducing economic waste and loss, greatly extending working life of equipment ${ }^{[2]}$.

\section{Application \\ Analysis on Automation in Technology Mechanical and Menu-}

Along with the advance and development of technology, the application of automation technology in mechanical design and manufacturing gradually expands, various large-sized complete sets of equipments gain successful research and development by virtue of computer technology, making mechanical design and manufacturing precision increase, and making integrated circuits manufacturing more and more highly integrated and scale-up. Specifically, the application of automation technology in mechanical design and manufacturing shows in the followings:

2.1Application of Computer Visualization in Mechanical Design and Manufacturing

This refers to converting abstract mechanical data information into visible and intuitive data information in mechanical design and manufacturing, operation staff can realize visual analysis, operation and process of mechanical design and manufacturing, roundly and dynamically control the whole process of mechanical design and manufacturing in real time, know performance of mechanical design and manufacturing products, and realize modification and optimation of mechanical design and manufacturing products ${ }^{\lfloor s]}$. Though combination of computer visualization and mechanical design and manufacturing, it can better realize computer aided design, for instance, CAD and CAM softwares can totally use mechanical design and manufacturing process to lower complexity of manual drawing, improve drawing efficiency, avoiding probability of deviation in mechanical design and manufacturing, improve working efficiency of mechanical design and manufacturing, and spur automation progrss of mechanical design and manufacturing.

2.2 Application of Computer Virtual Technology in Mechanical Design and Manufacturing

In applying computer virtual technology to mechanical design and manufacturing, automation mechanical design and manufacturing environment can be created which is very similar to real scene, it enables people's design concept to be simulated and displayed in virtual environment in advance, using computer virtual techonology to realize feasiblility verifying of mechanical design, thus making mechanical design and manufacturing more reasonable and scientific, and making interactivity between designers and mechanical design and manufacturing more unobstructed. Through application of virtual technology, practical testing costs of mechanical design and manufacturing products can be better reduced, and credibility and scientificity can be strengthened ${ }^{[4]}$.

\subsection{Computer Simulation Technology}

This uses computer to realize description of mechanical design and manufacturing, clearly, totally presents form, mathematical model, physical model of mechanical design and manufacturing products, making it as basis of mechanical design and manufacturing process. Then computer technology can be use to analyze and study it, fully analyzing product performance, making modifying operation of products more convenient. Under simulation experiment of mechanical design and manufacturing products, it can make mechanical design and manufacturing products more scientific and automatic, better guaranteeing quality of mechanical design and manufacturing products.

2.4 Application of Computer Integrated Manufacturing System in Mechanical Design and Manufacturing

In process of mechanical design and manufacturing, it involves various computer-aided technologies, such as computer-aided design and manufacturing, process planning, test, quality control, etc. These technologies can realize assistant application to mechanical design and manufacturing in different respects. However, though such technologies can better reduce mechanical design and 
manufacturing time and labor cost, it is not good in improvement of production efficiency in mechanical design and manufacturing and comprehensive competitivness ${ }^{[5]}$. Therefore, we should bring in computer integrated manufacturing system, systematically integrate computer-aided techonology process, construct and better unified mechanical design and manufacturing data model, take full advantages of integrated and unified data information sharing platform, realize effective communication and coordination in every single process of mechanical design and manufacturing, thus roundly improving comprehensive efficiency of mechanical design and manufacturing.

In applying computer integrated manufacturing technology, it takes electronic information, advanced materials, modern management theory as basis, it can fully take advantage of numerical control technique, computer-aided design and manufacturing technology, unconventional machining technology to realize integration of stuff, information and energy in process of mechnical design and manufacturing, while concurrent engineering is specifically shown in application of computer integrated manufacturing techonlogy to mechani cal design and manufacturing, it taks into consideration and plans the whole life cycle initially, reduces research time of mechanical manufacturing procucts and repeated design, and advoids unnecessary waste of resources based on overall producing needs ${ }^{[6]}$.

2.5 Application of Flexible Automation Production Technology in Mechanical Design and Manufacturing

This is a mechanical automation system concept first brought up by England, it takes production information of mechanical manufacturing products as basis, uses group technology, and coordinates material storage and transport system and digital processing technology equipment to realize group layout of mechnical processing objects based on specific needs, and choose proper, match able digital processing techonlogy equipment and material storage and transport system to better achieve processing purposes of different mechnical manufacturing products, and adjust timely according to market demands ${ }^{[7]}$.

This kind of flexible automation production technology applied to mechanical design and manufacturing, under constructing model from part to whole, dynamically monitors, adjusts and manages production plan, realizes data delivering from the botton to the upper information center, adjusts and control production according to the upper computer order, and better improves production efficiency of mechanical design and manufacturing.

2.6 Applicaton of Automatic Test Technology in Mechanical Design and Manufacturing

This is based on foundation of traditonal equipment and censors, its production test of mechanical design and manufacturing products can be without manual intervention, it only needs to be under condition of advanced information processing system, under condition of censor, signal conditioning, data processing and automatic test system operation, it can better improve product quality and realize safe test of mechanical design and manufacturing products ${ }^{[8]}$.

\section{Analysis on Development Direction of Mechanical Design and Manufacturing Automation}

\subsection{Virtualization}

In applying automation technology and computer informatin technology to mechanical design and manufacturing, it can realize information data transmission in production and manufacturing immediately by virtue of network simulation operation, and realize unobstructed communication and cooperation of different production process, targeting virtualization.

\subsection{Digitization}

This is formed by integrating mechanical design and manufacturing with computer science, network technology, and management science. In terms of various diagrams, data and techinfo, they all can be delivered and shared by digital. Supported by data base and multimedia, planning od product informatin, recombinatin and simulation can be realized, it can also achieve learning from each other according to real needs of customers, form dynamic uniting, coordinate design and manufacturing, targeting digitization ${ }^{[9]}$.

\subsection{Greenization}

In mechanical design and manufacturing, we need to take into account environment protection in process of design, manufacture, sale maintenance and recycling, advocate manufacturing concept of "Go Green", making it go with material civilization, spiritual civilizaiton and environmental civilization in social development, fully considering sustainable and harmonious social development, and leading mechanical design and manufacturing industry to develop targeting greenization.

\subsection{Intellectualization}

Mechanical design and manufacturing needs cooperation of man and intelligent machine, expanding mechanical design and manufacturing fields, construting and upgrading intelligent system of man and machine, better realize intelligent analysis, deduction, judge, conceiving and decision in mechanical design and manufacturing ${ }^{[10]}$.

\section{Conclusion}

All in all, development of mechanical design and manufacturing can't proceed without support of automation technology. In development and trend of mechanical design and manufacturing automation, we must further focus on relationship between man and products, relationship between products and nature, fully utilize various technologies and system of computer, promote mechanical design and manufacturing to 
develop towards intellectualization, personalization and environmental protection, fully recognize meaning and future blueprint of mechanical design and manufacturing automation.

\section{References}

[1]Ye qing $\mathrm{Bi}$. Research on Development Directionof Mechanical, Design Manufacture and Automation [J].Technology and Business.2014(10). [2] Yuzhi Zhang. Specialty Analysis of Mechanical Design and Manufacture Automation in the New Period[J]. Industrial\&Science Tribune. 2014(09) .
[3] Tong LI. Development Direction of Mechanical, Design Manufacture and Automation[J].China Science and Technology Investment. 2013(11).

[4] Chao Liu. Rsearch on Development

Direction of

Mechanical Design,Manufacture and Automation in China[J]. Henan Science and Technology. 2013(06).

[5] Yingfu Nong. Research on Development Direction of Mechanical Design, Manufacture and Automation[J]. Science and Technology Communication.2013(02).

[6] Cuihong Wu. On ProductionPractice Teaching of Mechanical Design, Manufacture and Automation[J].Guide toBusiness.
2012(09).

[7] R Light, D Gossard. Modification of Geometric Models through Variational Geometry, Computer-Aided Design.

[8] CM Luh, FA Adkins, EJ Haug. Working Capability Analysis of Stewart Platforms, Journal of Mechanical Design. [9] F Kimura, H Suzuki, H Ando. Variational Geometry Based on Logical Constraints and its Applications to Product Modelling, CIRPAnnalsManufacturing Technology.

[10] GA Kramer. Using Degrees of Freedom Analysis to Solve Geometric Constraint Systems, Acm Symposium on Solid Modeling Foundations \& Cad/cam Applications. 